\title{
Significações da reprovação escolar por alunos adolescentes de escola pública'
}

Meanings of school reprobation for adolescent students in public schools

Jéssica Augusta Santos* Universidade Federal de São João Del-Rei

Ruth Bernardes Sant'Ana** Universidade Federal de São João Del-Rei

Resumo Este artigo tem como objetivo apresentar uma experiência de pesquisa que buscou compreender as significações da reprovação escolar e os elementos a ela relacionados por alunos das últimas séries do Ensino Fundamental em escolas públicas do município de São João del-Rei, Minas Gerais. Os adolescentes pesquisados frequentam o ensino regular e o Programa Acelerar para Vencer (PAV), implementado pelo governo mineiro em 2008. Tomamos como embasamento as contribuições das perspectivas teóricometodológicas do interacionismo, sobretudo na sua vertente etnometodológica. $\mathrm{O}$ estudo revelou que os sentidos conferidos à reprovação oscilam entre a rejeição e a crença no seu poder disciplinador. Notamos na fala dos alunos que a reprovação só é vista como uma situação de fracasso para aqueles que vêem a escola como o único caminho para o sucesso profissional.

PALAVRAS-CHAVE: Reprovação escolar, Alunos adolescentes, Ensino Fundamental.

Abstract This paper aims to present a survey experience which sought to understand the meanings of school reprobation and the elements related to it by students on the last grades of elementary public schools in São João del-Rei, Minas Gerais. Presently, the investigated teenagers attended the regular teaching program and Programa Acelerar para Vencer (PAV), implemented by the state government in 2008. We take as basement some contributions from theoretical and methodological perspectives of interactionism, especially the ethnomethodological aspect. The study showed that meanings given to the school reprobation vary from rejection and belief in its disciplinary power. We noticed by the students' speeches that reprobation is only seen as a failure by those students who see school as the only way to achieve professional success.

KEYWORDS: School reprobation, Adolescent students, Elementar Schooling. 


\section{Introdução}

Este artigo tem como objetivo apresentar os resultados de um estudo que buscou conhecer, analisar e compreender as significações da reprovação escolar, por alunos adolescentes de três escolas da rede estadual de São João delRei, Minas Gerais. Entendia-se ser necessário tentar avançar, na construção de uma melhor compreensão sobre a percepção do alunado, visto que várias literaturas associam reprovações frequentes ao fracasso escolar, e que é escassa a proposta de ouvir o ponto de vista dos alunos sobre as significações que a reprovação escolar tem para eles.

Participaram da pesquisa alunos adolescentes de três escolas públicas matriculados no $9^{\circ}$ ano e alunos do PAV (Programa Acelerar para Vencer), com faixa etária entre 14 e 16 anos. A escolha desses alunos se deu pelo fato dos mesmos estarem no último ciclo do Ensino Fundamental e ser possível encontrar, nessas séries, alunos com uma ou mais reprovações em suas trajetórias escolares. As escolas onde esses alunos estudam, estão situadas nas proximidades do centro da cidade e, para frequentar as aulas, os adolescentes utilizam condução ou vão a pé. Alguns deles exercem outras atividades além das escolares, como, por exemplo, ajudar os pais desempenhando atividades domésticas, cuidar de irmãos mais novos ou mesmo exercer informalmente trabalhos remunerados. Parte desses alunos integra uma amostra de um estudo longitudinal ${ }^{2}$ dirigido pela segunda autora desse texto.

A educação é um direito de todos e um dever do Estado e da família, como garante a Constituição Federal de 1988, em seu art. 205 (BRASIL, 2011). Esse direito é ratificado pela Lei de Diretrizes e Bases da Educação Nacional no 9.394/1996, a qual apresenta a organização do sistema educacional brasileiro nos seguintes termos:

A Constituição determina que o direito à educação abranja a garantia não só do acesso e da permanência no ensino fundamental, mas também a garantia de padrão de qualidade como um dos princípios segundo o qual se estruturará o ensino. (apud SÁ EARP, 2006, p. 12)

Assim, para garantir a permanência dos alunos na escola e diminuir a defasagem idade/série, o governo de Minas Gerais instituiu, em 2008, um projeto de Aceleração da Aprendizagem ${ }^{3}$ - Acelerar para Vencer (PAV) - que busca, em tempo reduzido, a escolarização de alunos com histórias de reprovações no transcorrer do percurso escolar. O PAV tem como objetivos principais erradicar a cultura da repetência, corrigir a distorção idade/ano de escolaridade, implementar a "pedagogia do sucesso", fortalecer e desenvolver o autoconceito e a auto-estima dos alunos, além da superação da "pobreza crônica" das novas gerações.

A proposta pedagógica adotada no Projeto está centrada no aluno em situação de defasagem idade/série, sobretudo com repetências sucessivas, histórico de fracassos acumulados, e auto-estima fragilizada - razões pelas quais necessita 
de atenção especial, de professores bem preparados, currículo e materiais didáticos específicos e adequados. O Projeto se fundamenta, ainda, nas seguintes crenças e valores:

- Todo aluno é capaz de aprender;

- A educação deve promover o desenvolvimento na medida em que promove a atividade mental do aluno, responsável por transformá-lo em uma pessoa ímpar;

- A escola deve ser capaz de atender à diversidade;

- A escola deve ser capaz de oferecer a cada aluno um currículo necessário para seu progresso;

- A escola deve tornar acessível ao aluno aspectos da cultura que são fundamentais ao seu desenvolvimento pessoal;

- Os conteúdos curriculares são meios para aquisição e desenvolvimento das capacidades e habilidades básicas necessárias à inserção do aluno na vivência cidadã;

- O professor é mediador entre o aluno e o conhecimento, porque entende a educação como prática social transformadora e democrática (DOCUMENTO BASE, 2008 p. 8).

Ao buscarmos, nas falas dos alunos, as significações da experiência da reprovação acabamos por abranger os alunos do PAV e, assim, tivemos acesso às metas estabelecidas pelo documento-base e pela proposta curricular desse programa de correção do fluxo escolar. Desse modo, as questões que nortearam este trabalho foram: i) que significações a reprovação assume, na trajetória escolar, segundo os alunos investigados?; ii) a que aspectos do processo de escolarização a reprovação está relacionada? e iii) como esta repercute em suas vidas?

Para responder a tais questões, utilizamos os seguintes procedimentos de investigação: observação em sala de aula, que contribuiu para um conhecimento maior do cotidiano escolar vivido pelos adolescentes; entrevista para conhecimento mais abrangente sobre os estudantes, com foco na sua formação no contexto da escola, da família e nas relações com os amigos; por último, entrevista específica sobre a reprovação escolar.

\section{Reprovação e fracasso}

Ao final do século XX, com o Ensino Fundamental quase universalizado, a escola brasileira, instituída primeiramente para educar e formar a elite nacional, desenvolveu lentamente o atendimento à população de baixa renda. Porém, mesmo depois do incremento, na democratização do acesso à educação escolar, ocorrido a partir da década de 60 do século XX, mantiveram-se as características da escola tradicional seletiva no que diz respeito à organização do processo de ensinoaprendizagem, pois, conforme Jacomini (2009), todos os elementos que compõem a atividade educativa escolar são pensados e organizados em função da média de um quantum que se pode aprender numa determinada idade que corresponde a uma série escolar. 
A autora defende a ideia de que essa forma de organizar o ensino, muitas vezes em contradição com as necessidades e dinâmicas individuais, produziu um grave problema para as instituições escolares. Desse modo, a solução encontrada e legitimada historicamente para os alunos que não têm um desempenho escolar adequado foi a reprovação (Op. Cit.).

Segundo Moura e Silva (2007), a concepção semântica do termo "reprovação" está vinculada a sentimentos de rejeição, condenação, incapacidade, em uma abordagem complexa e muito delicada, que nega um ideal de sucesso, angustiando, em maior ou menor grau, todos os envolvidos no processo.

Desde o início do século $\mathrm{XX}$, diversas pesquisas têm investigado as causas da reprovação. A princípio, associava-se a reprovação escolar a aspectos de origem congênita, hereditárias ou de disfunções neurológicas. Posteriormente, novas teorias atribuíam as causas da reprovaçaõ a fatores externos à escola, como a questão cultural e condição socioeconômica. Teorias raciais e psicológicas também passaram a ser investigadas. Mais recentemente, novas pesquisas têm assinalado fatores intra-escolares, bem como as políticas educacionais e os sistemas de ensino como responsáveis pelos altos índices de evasão e reprovação escolar.

Assim, no transcorrer do século XX, houve um aumento da sensibilidade acadêmica e social sobre as relações entre reprovação e fracasso escolar. Por isso, ocorreram várias tentativas, bem ou mal sucedidas, com vistas à diminuição de sua ocorrência na escola pública. Patto (1991), ao investigar a respeito da produção do fracasso escolar, afirma que, já na primeira metade do século $X X$, era possível identificar algumas recomendações governamentais com o intento de modificar os elevados índices de evasão e repetência que afetavam o quadro nacional.

No Brasil, têm-se a crença de que, repetir a série é bom para o aprendizado do aluno. Em adição a isso, a "pedagogia da repetência" recorre à reprovação como mecanismo voltado para motivar os alunos a aprender, já que as tarefas que compõem o ofício do aluno não são motivadoras em si, devendo a motivação ser garantida por dispositivos externos ao processo pedagógico. Geralmente, as turmas consideradas "fracas" por causa da repetência acabam por gerar mais repetentes, criando um circulo vicioso, que favorece o fracasso escolar. Costa Ribeiro e Paiva (1995) apontam para o uso da reprovação, ou mesmo sua ameaça, como manifestação de um autoritarismo docente, quando os métodos de ensino não são efetivos. Desse modo, a ameaça da reprovação constitui o único instrumento de motivação, atestando que o "fracasso" é do aluno.

Charlot (2000) afirma que, ao se estudar o "fracasso escolar" é preciso definir um objeto que possa ser analisado. Ainda, segundo o autor, o fracasso não é algo em si, algo que conta com uma única definição, amplamente aceita. O que existe são alunos em situação de fracasso (o que remete à história daquele que fracassa), alunos, que não conseguem aprender, histórias escolares que terminam mal, e são essas histórias que deveriam ser analisadas. 


\title{
Métodos utilizados
}

As questões norteadoras do estudo conduzem a uma abordagem metodológica qualitativa, guiada pelas contribuições do interacionismo simbólico, conjugado com a etnometodologia da escola. Essas duas metodologias possuem muitos pontos em comum, principalmente no tocante à ideia de que deve o pesquisador registrar o mais fielmente possível as falas entre os sujeitos em cada situação, procurando trazer o ambiente sócio-afetivo em que isso se dá.

Para o interacionismo simbólico, o conhecimento sociológico só pode ser percebido pelo pesquisador a partir da observação direta e imediata das interações entre os atores sociais, das ações práticas dos atores e o sentido que eles atribuem aos objetos, às situações, aos símbolos que os cercam, pois é nesses pormenores que os atores constroem seu mundo social. Ou seja, o significado social dos objetos se deve ao fato de lhes darmos sentido no decurso de nossas interações (COULON, 1995). O autor define a etnometodologia como uma

\begin{abstract}
pesquisa empírica dos métodos que os indivíduos utilizam para dar sentido e ao mesmo tempo realizar as suas ações de todos os dias: comunicar-se, tomar decisões, raciocinar. Para os etnometodólogos, a etnometodologia será, portanto, o estudo dessas atividades cotidianas, quer sejam triviais ou eruditas, considerando que a própria sociologia deve ser considerada como uma atividade prática. (COULON, 1995, p. 30)
\end{abstract}

Nessa perspectiva, com o propósito de investigar as significações reveladas na compreensão de alunos da escola pública acerca da reprovação escolar, construiu-se um roteiro de trabalho reunindo dois procedimentos de investigação: observação em sala de aula e entrevistas individuais com os adolescentes participantes, buscando identificar em seus relatos características particulares, quanto aos significados que transcorrem e seus posicionamentos frente à reprovação escolar, já que todos os alunos entrevistados passaram por experiências de reprovação em seu processo de escolarização.

As observações em sala de aula foram realizadas em duas escolas da rede estadual de São João del-Rei, Minas Gerais. Quando necessário, identificaremos as escolas como EE1 (Escola Estadual 1) e EE2 (Escola Estadual 2). Foram observadas três turmas, sendo duas do $9^{\circ}$ ano do Ensino Fundamental em 2011, da EE1 e uma turma do Projeto Acelerar para Vencer da escola EE2, sendo que este projeto se destina aos alunos do Ensino Fundamental com distorção idade/série de pelo menos dois anos, para estudos correspondentes ao $8^{\circ}$ e $9^{\circ}$ anos. As observações foram realizadas entre agosto de 2010 e julho de 2011, totalizando 120 horas de aulas assistidas, todas relatadas em diários de campo e, em seguida, transcritas e arquivadas no banco de dados da pesquisa.

Também foram realizadas entrevistas semi-estruturadas e individuais por propiciarem a flexibilidade necessária para os atores terem liberdade de discorrer sobre as questões abordadas, informando e opinando sobre o tema proposto e 
expressando, inclusive, sentimentos, crenças e valores. As entrevistas foram todas gravadas com a autorização dos sujeitos, transcritas e analisadas de modo que possibilitassem registrar, com a maior fidelidade possível, os dados obtidos. As entrevistas foram realizadas no período de julho a dezembro de 2011, na própria escola, em dia e horário pré-estabelecido, sendo que os alunos entrevistados se encontravam em três escolas diferentes. Foram realizadas dez entrevistas e a escolha por esses adolescentes se deu pelo fato de quatro deles fazerem parte da amostra de um estudo longitudinal em desenvolvimento desde 2001, e seis por serem alunos do PAV. Tais entrevistas foram norteadas por um roteiro elaborado e discutido no grupo de pesquisa coordenado pela segunda autora deste trabalho.

\section{Análise dos resultados - significações da reprovação escolar}

Passemos, agora, à apresentação do que constatamos por meio do estudo realizado. Apresentaremos os aspectos que nos permitiram identificar os elementos trazidos pelos alunos sobre a reprovação, verificando o balanço que eles fazem de sua trajetória escolar após vivenciar a repetência. A ênfase, no ponto de vista discente, se justifica porque enquanto essa questão é amplamente abordada e debatida em pesquisas, ainda é pequeno o número de estudos dedicados a analisar a opinião dos alunos sobre essa temática.

Uma das primeiras constatações possíveis, a partir do trabalho realizado, é a ideia partilhada de que a reprovação faz parte da educação escolar ou é vista como necessária ao controle dos processos de ensino-aprendizagem. Essa fala é corrente na escola, aparecendo com muita freqüência na sala de aula. A título de ilustração, veja-se o registro de uma situação em que isso aconteceu:

\section{A professora se levantou e começou a transcrever a matéria no quadro, dizendo que muitos alunos não estavam com a nota boa e que seria melhor que eles copiassem o que ela escrevia na lousa, caso não quisessem repetir o ano. Os alunos começam a copiar. (OBSERVAÇÃO EM SALA DE AULA, 9 ano - 8a série EE1, 13/05/11)}

Tal atitude nos mostra que a ameaça da reprovação constitui um dispositivo de controle do comportamento dos alunos. Nessa fala, o que parece mais importante não é a aprendizagem propiciada pelo conteúdo ministrado, mas a obrigação da cópia. De maneira semelhante, as falas dos adolescentes repetem a crença, no poder disciplinador da reprovação, mas também acentuam um papel importante na aquisição do conteúdo escolar. A entrevista de Maria ilustra isso:

Pesq.: Você acha que a reprovação ajuda ou atrapalha a vida dos adolescentes?

Maria: Eu acho que ajuda, por que [...] ah, é um ensino mais reforçado, mais um ano pra você aprender mais aquilo que você já sabia, mas não prestou atenção, é mais um ano pra você aprender. (ENTREVISTA COM MARIA, ${ }^{4} 1$ REPROVAÇÃO, EE2, 08/12/2011) 
Nas duas situações, fica evidente que o único responsável pela reprovação escolar é o aluno. É ele que resiste ou não à realização da tarefa, não presta atenção nas aulas e não aprende. Na verdade, as falas dos entrevistados evidenciam a incorporação das representações sociais dominantes sobre as causas da reprovação, apesar de considerarem maléfica a perda de um ano escolar, o que podemos observar no depoimento seguinte:

Patrícia: Às vezes eu acho que ajuda, porque se a pessoa não vai bem durante o ano, ela tem a oportunidade de aprender aquilo que ela não conseguiu. Atrapalha porque [o aluno] perde um ano de bobeira. (ENTREVISTA COM PATRÍCIA, 2 REPROVAÇÕES, EE2 - PAV, (01/12/2011)

Quando indagada se era a favor ou contra a reprovação escolar, outra adolescente respondeu:

Dayana: Ah, às vezes eu acho que é favor, às vezes eu acho que é contra, mas às vezes eu penso que é bom porque mostra pro aluno [como] ficar melhor, porque passar sem saber, o que adianta?. (ENTREVISTA COM Dayana, 3 REPROVAÇÕES, EE2 - PAV, $(01 / 12 / 2011)$

Os enunciados exprimem a crença de que a reprovação, apesar de atrapalhar o fluxo escolar, traz benefícios por ser uma nova possibilidade de aprendizado ou uma forma de conscientização do discente sobre suas dificuldades.

Como pudemos verificar, nesses casos, o adolescente tem a convicção de que a reprovação o fará obter melhores resultados na série a ser repetida. Repetir a série representa, portanto, uma nova chance e, por conseguinte, um ganho no aprendizado. A pouca aprendizagem é notada por eles como conseqüências de seus atos. Poucas vezes, os alunos criticaram a escola ou os professores, como nos mostram os excertos de entrevistas com quatro alunos:

Pesq.: Quais foram os motivos que te levaram à reprovação?

Maria: Falta de estudo, eu conversava muito, e não prestava atenção nas aulas, aí eu deixei pra estudar no final do ano, aí quando chegou no final do ano, não dava mais tempo. (ENTREVISTA COM MARIA, 1 REPROVAÇÃO, EE2, $08 / 11 / 11)$

Sara: A primeira bomba que eu tomei foi mais pela sala, $90 \%$ da sala tomou bomba, ninguém queria nada com nada, era brincadeira a aula inteira, era conversa a aula inteira e acabou que foi juntando, foi juntando, foi juntando, acabei tomando bomba. Aí eu peguei e repeti esse ano a 6a serie, aí pra mim passar pra $7^{a}$ depois eu fiquei devendo duas matérias e do outro ano também foi brincadeira, aí na $7^{a}$ série acumulou essas duas matérias mais as outras seis matérias, então eu não consegui passar. (ENTREVISTA COM SANDRA, 2 REPROVAÇÕES, EE2, $(21 / 11 / 11)$ 
Fernando: Ah, todas duas eu brincava bastante, acho que falta de atenção, falta de compromisso, acho que é isso. (ENTREVISTA COM FERNANDO, 2 REPROVAÇÕES, EE2 - PAV, $(21 / 11 / 2011)$

Marcelo: Falta de estudo [risos]. Malandragem mesmo, foi isso. Eu resolvi estudar de última hora. (ENTREVISTA COM MARCELO, 1 REPROVAÇÃO, EE1 (20/11/11)

De modo geral, esses alunos relacionam os principais motivos de suas reprovações a fatores tais como indisciplina, desatenção, negligência com as tarefas escolares e desinteresse pelo estudo. Nessa concepção geral predominam, portanto, a falta de atenção e desinteresse, como se pode observar na situação abaixo:

\begin{abstract}
Enquanto a professora não chegava à sala, uma aluna da amostra e mais duas colegas falavam sobre a aula dizendo que a professora era muito "chata" e que não gostavam da disciplina por ela ministrada. Estando perto das alunas, perguntei de quais disciplinas elas gostavam, e responderam: "de nenhuma, esse ano todas estava muito chatas e que no ano passado gostavam muito de ciências". A professora chegou e entramos na sala. A aula é de Português, a professora começou a transcrever uma atividade no quadro, enquanto os alunos conversavam e transitavam pela sala o tempo todo e ficam quietos somente quando a professora começa a explicar a tarefa, que consistia em escrever uma carta. Uma aluna teve dúvidas de como iniciar a tarefa e a professora explicou novamente. Passados alguns minutos, ela se vira para trás e começa a conversar com uma colega, perguntando em seguida o que deveria para ser feito. Alguns alunos começam a fazer a carta. Um deles nem sequer inicia a tarefa; parece estar concentrado quebrando uma régua de plástico e fazendo barulho, enquanto outro colega empurra a carteira, também fazendo barulho. Enquanto a sala parecia estar de "pernas para o ar", a professora estava sentada em sua mesa, alheia ao que estava acontecendo. (OBSERVAÇÃO EM SALA DE AULA, EE1, 29/04/11)
\end{abstract}

Percebemos que alguns professores apresentam comportamentos indiferentes em relação à recusa dos alunos ao conteúdo e à pedagogia por eles adotada. Incapazes de modificar essa realidade, acabam por recorrer à ameaça da repetência como tentativa de controle do comportamento discente.

Não obstante, é voz dominante a afirmação que, refazer uma série propicia melhor aprendizado para o aluno e que, assim, ele pode continuar os estudos. A partir de falas, como as citadas acima, fica em questionamento se a reprovação consegue diminuir a resistência do aluno ao saber, se vai passar a gostar do que não gostava ou se vai aprender apenas com vistas à avaliação e depois esquecer o conteúdo aprendido.

Isso nos sugere que existem outros elementos além do desinteresse puro e simples do aluno. As falas dos entrevistados indicam um problema de 
legitimidade do conteúdo ou da forma como este é ministrado, ao ponto dos alunos mostrarem que não gostaram de nenhuma das unidades curriculares do ano de 2011 , no $9^{\circ}$ ano.

Esses dados ratificam que a reprovação escolar no Brasil pode, de fato, comprometer a auto-estima dos alunos, produzindo certa descrença em sua capacidade de aprender, o que suscita incômodo, insegurança e tristeza. Essas significações da experiência aparecem na fala de alguns entrevistados quando refletem sobre como se sentem como alunos reprovados:

Dayana: Ah, é ruim, fica pensando, parece que não tem capacidade própria de conseguir fazer o negócio [passar de ano] da primeira [vez]. (ENTREVISTA COM DAYANA, 3 REPROVAÇÕES, EE2 - PAV, 01/12/11)

Fernando: Incomodado de está repetindo de novo, de está na mesma série. (ENTREVISTA COM FERNANDO, 2 REPROVAÇÕES, EE2 - PAV, 21/11/2011)

Maria: Ah bem triste né, tem uns que, que já não gostam de estudar mesmo, nem liga, pra eles tanto faz reprovar ou não, mas tem pessoa que estuda e que se esforça mesmo e não consegue. Aí ela fica bastante triste por causa disso. (ENTREVISTA COM MARIA, 1 REPROVAÇÃO, EE2, 08/12/11)

Sandra: Depende muito da cabeça de cada um, porque uns alunos não tão nem aí, eu tomava bomba eu ria de uma orelha até a outra, agora eu tomei bomba o ano passado, aí eu vi que o bicho tava pegando pro meu lado, que o bicho ia pegar pro meu lado, que não ia ser daquele jeito. Mas depende muito da cabeça de cada um, pra falar, a primeira bomba que eu tomei, eu ria: ' ah tomei bomba, problema, mais um ano, eu não me importava.' Agora a segunda bomba que eu tomei, eu evolui, do sorriso que tava no rosto, já bateu a tristeza: 'nossa mais um ano que eu vou ter que entrar no mesmo lugar, vou entrar na mesma coisa, do mesmo jeito. (ENTREVISTA COM SANDRA, 2 REPROVAÇÕES, EE2 - PAV, 21/11/2011)

Concordamos com Perrenoud (2002) quando afirma que, de fato, um aluno que a escola declara insatisfatório pode não se considerar assim, de acordo com seus próprios critérios, do mesmo modo que seus pais, parentes e amigos podem defender esse mesmo ponto de vista.

Quando não conseguem tornar significativo para o aluno o trabalho escolar, os programas de aceleração apenas corrigem os fluxos, sem manejo do processo que impede a aprendizagem desses adolescentes. Quando isso ocorre é comum que a maior parte dos alunos jogue o jogo institucional e procure estratégias para lidar com o sistema educacional da reprovação, com esquivas e recusas a uma parte expressiva das tarefas que compõem o ofício do aluno. Entre esses comportamentos incluem atitudes como estudar apenas para obter notas, de maneira que, na semana seguinte, os estudantes nada sabem sobre as questões que acertaram na prova; recorrer a estratégias como a "cola" ou realizar apenas as 
tarefas avaliativas. Assim, programas como o PAV correm o risco de se tornarem apenas um paliativo à reprovação, "empurrando" para o futuro a resolução ou não dos entraves na escolarização.

\section{Considerações finais}

Este trabalho propôs compreender as significações dos alunos, que já vivenciaram a reprovação escolar, a partir da escuta do que estes expressam no interior da sala de aula e nas situações de entrevista. Inicialmente, as perguntas que nortearam nossa pesquisa foram: que significações a reprovação assume na trajetória escolar segundo os alunos investigados? A que aspectos essa experiência está relacionada? E como esta repercute em suas vidas? A partir dessas questões, foi possível identificar as significações da experiência de reprovação nesse momento dos seus percursos escolares.

Verificamos que os sentidos conferidos à reprovação oscilam. Se, de um lado, sua rejeição se deve à perda de um ano letivo, sua aceitação decorre das crenças no seu papel como facilitador de uma maior sedimentação da aprendizagem e no seu poder disciplinador, ou seja, na sua capacidade de provocar mudança de comportamento discente para melhor.

Diante do exposto, é preciso recolocar algumas reflexões em torno da reprovação. Nota-se que repetir o ano é como uma segunda chance para esses alunos e um reforço aos estudos, de modo que todos concordaram que o único ponto negativo na reprovação é a perda de tempo, o atraso na vida escolar. A pesquisa nos mostrou que o impacto da segunda reprovação é maior e provoca mudanças na vida escolar daqueles alunos que vivem mais de uma reprovação no decorrer de sua trajetória. A reprovação só é vista como fracasso pelos alunos que vêem a escola como o caminho para o sucesso na vida profissional e atribuem a si mesmos a causa do bom ou mau desempenho escolar. Sentimentos de frustração, insegurança e baixa auto-estima diante das reprovações se mostraram mais visíveis no interior desse grupo.

Não notamos diferenças significativas nas falas dos alunos quando comparamos os que freqüentam o ensino regular e os inseridos na turma do PAV. Tanto um grupo quanto o outro compartilham de algumas opiniões idênticas quanto à reprovação. Os alunos integrantes do Projeto Acelerar para Vencer se dizem satisfeitos por estarem lá e não reclamam diferenças no tratamento dado tanto pela escola quanto pelos professores à sua turma. Apesar disso, não é incomum que alunos que não fazem parte de classe de aceleração (do $9^{\circ}$ ano) categorizem os matriculados no PAV como constituintes de uma turma muito "bagunçada", que "não quer nada com nada" ou "excluída da escola". Com isso, notamos que as falhas estruturais ocorridas, na escola ou no Projeto Acelerar para Vencer, são identificadas pelos adolescentes como resultantes de falhas deles próprios, pois frequentemente culpam a si mesmos ou aos outros alunos por tais falhas.

Contudo, vale ressaltar, com Jacomini (2008), que a superação das práticas de reprovação depende da promoção como legitimadora da aprendizagem 
e da busca, nos pressupostos de um processo educativo contínuo, uma prática que rompa com a dicotomia promoção/reprovação. Nessa perspectiva, podemos concluir que são muitas as variáveis que compõem a trajetória escolar do sujeito e que tornam singular cada caso, cada percurso, cada história de fracasso ou de sucesso. Desse modo, os "sistemas educacionais fariam melhor se esclarecessem seus objetivos de formação e se colocassem a avaliação de acordo com seus objetivos, e não o inverso". (PERRENOUD, 2002, p. 26).

\section{Referências}

BRASIL. Constituição da República Federativa do Brasil (1988). Brasília, Senado, 1988. Disponível em: <http://www.dji.com.br/constituicao_federal/cf205a214.htm>. Acesso em: 18 dez. 2011.

CHARLOT, B. Da relação com o saber: elementos para uma teoria. Porto Alegre: Artes Médicas Sul, 2000.

COSTA RIBEIRO, S; PAIVA, V. Autoritarismo social e educação. Educação \& Sociedade, ano XVI, n. 53/especial, p. 634-647, dez. 1995.

COULON, A. Etnometodologia e educação. Petrópolis: Vozes, 1995.

JACOMINI, M. A. Reprovação escolar na opinião de pais e alunos: um estudo sobre os ciclos e a progressão continuada na Rede Municipal de Ensino de São Paulo. 2008. Tese (Doutorado em Educação) - Faculdade de Educação, Universidade de São Paulo, São Paulo.

JACOMINI, M. A. Educar sem reprovar: desafio de uma escola para todos. Educação e Pesquisa, São Paulo, v. 35, n. 3, p. 557-572, set./dez., 2009.

MOURA, E. M.; SILVA, J. C. da. Reprovação escolar: discutindo mitos e realidade. Disponível em: <www.diaadiaeducacao.pr.gov.br/portals/pde/arquivos/370-2.pdf>. Acesso em: 10 jan. 2012.

PATTO, M. H. S. A produção do fracasso escolar. São Paulo: T. A. Queiroz, 1991.

PERRENOUD, P. A prática reflexiva no ofício do professor. Porto Alegre: Artmed, 2002.

SÁ EARP, M. de L. A cultura da repetência em escolas cariocas. Tese de Doutorado em Antropologia Cultural. Programa de Pós-Graduação em Sociologia e Antropologia. Universidade Federal do Rio de Janeiro. UFRJ/IFCS. Dezembro 2006. Disponível em: <www. bdae.org.br/dspace/bitstream/123456789/820/1/tese.pdf>. Acesso em: 18 nov. 2011.

SECRETARIA ESTADUAL DE EDUCAÇÃO DE MINAS GERAIS. Projeto de aceleração da aprendizagem: Acelerar para vencer. Documento Base. 2008.

\footnotetext{
Notas

${ }^{1}$ As autoras agradecem à FAPEMIG pelo financiamento da pesquisa que originou o presente artigo.

${ }^{2}$ Consiste em uma pesquisa de caráter longitudinal, em desenvolvimento desde 2001 e voltada para o acompanhamento das trajetórias escolares de um grupo de estudantes desde a pré-escola.

${ }^{3}$ Extraído do documento base do Projeto Acelerar para Vencer do Governo do Estado de Minas Gerais.

${ }^{4}$ Todos os nomes de alunos e professores citados neste trabalho são fictícios.
} 
* Graduação em Psicologia pela Universidade Federal de São João Del-Rei (UFSJ). Estuda os processos educativos. São João del Rei, Minas Gerais - Brasil.

** Professora Doutora da Universidade Federal de São João Del-Rei (UFSJ), Departamento das Psicologias.

São João del Rei, Minas Gerais - Brasil.

\section{Correspondência}

Ruth Bernardes Sant'Ana - Universidade Federal de São João Del-Rei, Departamento das Psicologias. Praça Dom Helvecio, 74, Fábricas, CEP: 36300-000 - São João del Rei, Minas Gerais - Brasil.

E-mail: ruthbs@ufsj.edu.br-jessicanaza@yahoo.com.br

Recebido em 30 de março de 2012

Aprovado em 16 de junho de 2013 